\title{
Bioseguridad en odontología en tiempos de pandemia COVID-19
}

\section{Dra. Andrea Badanian}

Profa. Int. Cátedra Microbiología Gral. y Bucodental, Facultad de Odontología, UdelaR. ORCID: 0000-0001-8397-6639

\section{Introducción}

En diciembre de 2019, casos de neumonía fatales se presentaron en la ciudad de Wuhan, China. Tras su análisis genético, se pudo determinar que el agente causal era un coronavirus no conocido.

La enfermedad se nombró enfermedad del coronavirus del 2019 (COVID-19). El virus que inicialmente se lo nombró 2019-nCoV luego fue renombrado SARS coronavirus-2 (SARSCoV-2). ${ }^{(1,2)}$

\section{Agente viral y aspectos de atención en la práctica odontológica}

El virus SARS-CoV-2 agente causal de la patología COVID-19 forma parte de la familia Coronaviridae. ${ }^{(3,4)} \mathrm{Si}$ bien comúnmente se lo nombra como coronavirus, esta denominación representa una familia de virus que contiene además del que produce la pandemia actual, el SARS coronavirus (SARS-CoV) que provocó la epidemia SARS en 2002-2003 con una mortalidad del 10\% y el MERS-CoV (síndrome respiratorio del Medio Este) que tuvo una tasa de mortalidad del $37 \%$. $^{(1)}$

Hay aspectos que identifican a los virus en general, a éste en particular así como a la virosis COVID-19 que nos parece pertinente presentar porque permitirá entender elementos a considerar en el manejo y control de este virus en la práctica odontológica que son:

- la estructura viral

- la vía de transmisión

- la tasa de transmisión

- la capacidad infectiva

- la carga viral

- el tiempo de supervivencia 


\section{Estructura viral}

En cuanto a la estructura, mencionar que los virus son parásitos intracelulares estrictos por lo cual requieren de células para multiplicarse. Portan material genético que puede ser ADN o ARN y por fuera una capa de proteínas (cápside). Adicionalmente, muchos virus presentan una tercer estructura lipoproteica (envoltura) que envuelve al material genético y la cápside. La mayoría de los virus con envoltura poseen espículas de naturaleza glicoproteica donde se encuentran las proteínas de fijación que se unirán a receptores celulares. ${ }^{(5)}$

En lo que respecta a los coronavirus son virus ARN envueltos. Se denominan coronavirus porque presentan espículas en su superficie que le dan una semejanza a una corona. ${ }^{(4)} \mathrm{En}$ el caso del SARS-CoV-2, las glicoproteínas de las espículas se unen al receptor ACE-2 presente en corazón, pulmones, riñones y tracto gastrointestinal ${ }^{(1)}$.

Las glicoproteínas del SARS-CoV-2 denominadas S, están conformadas por la subunidad S1 responsable de unirse a los receptores de las células y la subunidad S2 responsable de la fusión entre las membranas celular y viral. Para que la fusión ocurra la proteína $\mathrm{S}$ debe ser clivada por proteasas de la célula que permita la exposición de las secuencias de fusión y por tanto necesarias para la entrada a la célula. Estas proteasas son las furinas. ${ }^{(6)}$

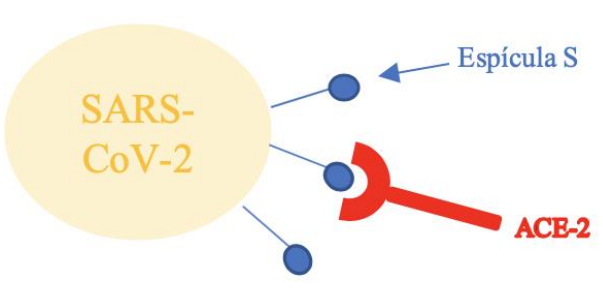

Figura 1. Esquema de espícula S virus SARS-CoV-2 y receptor célula ACE-2

El primer punto a mencionar es que al tratarse de un virus ARN, éstos presentan tasas de mutación altas porque a diferencia de las ADN polimerasas, ARN polimerasas no tienen capacidad de detectar y corregir los errores. Por otro lado, los coronavirus presentan una alta tasa de recombinación, característica que comparten con los virus segmentados. Esta alta tasa de recombinación resulta en una evolución rápida del virus y en la formación de nuevas cepas. ${ }^{(7)}$

El segundo punto está relacionado a que son virus envueltos lo que son los más simples de inactivar. Esto representa una ventaja en el uso de agentes químicos (antisépticos o desinfectantes) que afecten los lípidos y por tanto logren su inactivación. 


\section{Vía de transmisión}

Es directa, interpersonal principalmente por inhalación de gotitas respiratorias (gotitas de Flügge) e indirecta por el contacto con superficies contaminadas (fomites). ${ }^{(2,8)}$

Se sospecha que la transmisión no está sólo limitada al tracto respiratorio y que la exposición ocular puede ser una vía de ingreso del virus. (8)

Por tanto, las gotitas pueden depositarse en las mucosas nasal, oral y conjuntiva y a partir de ahí producir la infección.

La transmisión interpersonal directa o indirecta a través de saliva también puede ser una vía de transmisión y se ha reportado la presencia de partículas virales en la saliva de individuos infectados. (8)

Por otro lado, estudios mostraron que ACE-2 puede estar expresado en las células epiteliales de cavidad oral en particular en lengua. (9)

Si bien no está confirmado, se sugiere que la vía aérea a través de aerosoles que se producen durante los procedimientos médicos (lo que incluiría los generados en la atención odontológica) puede ser otra vía de transmisión y también está en duda la transmisión fecaloral. $(3,8)$

Al respecto de la transmisión por vía aérea el CDC menciona que la transmisión por esta vía es actualmente incierta. Sin embargo, la transmisión por esta vía de persona a persona a distancias largas es improbable. ${ }^{(10)}$ Por este motivo, en el caso de la atención odontológica donde la distancia es mínima adquiere especial relevancia la atención a esta vía.

Por otro lado, hay que poner especial cuidado en que en muchos procedimientos dentales se generan aerosoles y gotas con agentes infecciosos. Estos pueden afectar a los profesionales de salud pero también extenderse a superficies y entorno de la clínica.

En este punto cabe mencionar que el uso de barreras así como los aspectos de desinfección deben ser revisados a efectos de evaluar posibles cambios o ajustes a lo que actualmente se utiliza.

\section{Tasa de transmisión}

Respecto a la tasa de transmisión que define la cantidad de gente que un hospedador infectado puede contagiar, se estima actualmente entre 2.24 y 3.58 si bien la OMS lo estima entre 1.4 a 2.5. A efectos comparativos la gripe estacional ronda entre 1.1 y 2.3 (dependiendo de la región e inmunización). Esta mayor tasa puede deberse a un mayor período prodrómico lo que aumenta el período en el cual el hospedador infectado puede contagiar. (1)

Por otro lado tener en cuenta que la transmisión podría ocurrir en contacto con pacientes asintomáticos. ${ }^{(11)}$ 


\section{Capacidad infectiva}

Representa uno de los mayores desafíos del SARS-CoV-2. Gran parte del problema epidemiológico está relacionado a su gran capacidad infectiva. Se ha visto que el SARS-CoV2 se une al menos 10 veces más firmemente que el de SARS-CoV. (12)

La proteína de la espícula contiene un sitio que reconoce y se activa por la furina que es una enzima de las células del hospedador presente en varios órganos como hígado, pulmones e intestino delgado. Esto significa que el virus puede potencialmente atacar varios órganos al mismo tiempo. ${ }^{(12)}$

\section{Carga viral}

Ciertos estudios demostraron que la carga viral del SARS-CoV-2 alcanza su punto máximo en la primer semana del inicio de la enfermedad (antes del día 6) y también que los casos graves tienen un período más extenso de eliminación del virus. ${ }^{(11,13)}$ Hay que tener en cuenta que a mayor carga viral implica mayor posibilidad de contagio; esto también representa un desafío ya que esta mayor capacidad de contagio ocurriría cuando el paciente está empezando a tener los primeros síntomas y/o no ha sido diagnosticado.

\section{Tiempo de supervivencia}

Por último, en cuanto al tiempo de supervivencia la evidencia actual sugiere que una vez que las gotas se depositan en las superficies pueden mantenerse viables por horas a días dependiendo del material y aumentando su supervivencia en ambientes fríos y secos. ${ }^{(1-2)}$

\section{Posibles impactos en aspectos de bioseguridad en la práctica odontológica}

En primer lugar, hay que mencionar que si bien el objetivo de este documento es revisar y poner a punto los procedimientos que aseguren la protección del paciente y el personal de salud frente a esta pandemia, no debemos olvidar uno de los principios básicos de la bioseguridad que se basa en que el trabajador expuesto debe seguir las precauciones universales frente cualquier individuo sin importar si conocemos o no su serología $u$ otros elementos (como estrato social, etc) ya que potencialmente puede portar y transmitir microorganismos patógenos. 
No obstante, el objetivo de este trabajo es revisar, ajustar y profundizar en técnicas teniendo en cuenta que el momento actual es en un contexto crítico de la pandemia, motivo por el cual se pueden llegar a tomar ciertas decisiones o pautas particulares asociadas referidas a éste.

En términos generales los procedimientos y técnicas de bioseguridad se mantienen vigentes, pero estamos en un momento en el cual se está en plena fase de contagio comunitario. En este sentido, esta revisión se sitúa en el momento en el cual se comienza la atención odontológica, pero aún estamos en un momento en que la mayoría de la población no está inmune y además se busca "aplanar" la curva de contagio. Este punto es importante ya que las prácticas de bioseguridad buscan evitar y minimizar ésta y otras enfermedades infecciosas, pero esto no se circunscribe únicamente al acto de atención odontológica en sí, sino que trasciende a éste y aparecen medidas como, por ejemplo, espaciar la agenda de atención para minimizar los tiempos de contacto entre pacientes en la sala de espera.

Por este motivo, a continuación, se expondrá en términos generales si el procedimiento estándar de bioseguridad se mantiene o refuerza con algunas medidas adicionales por el contexto actual.

Otro punto no menor, es que aún se está en plena etapa de investigación del virus y la infección por él producida, por lo cual hay aspectos que aún están bajo estudio y evolución. Esto implica que los protocolos durante este brote estarán bajo constante revisión y actualización adaptándose al momento de la pandemia con el objetivo de disminuir el riesgo de contagio.

El siguiente trabajo está basado en la revisión y selección de la literatura disponible al momento Para algunos aspectos aún no existe evidencia científica de respaldo por tanto hay recomendaciones que están basadas en el marco teórico y la similitud con otros virus (como el SARS-COV-1).

\section{Recomendaciones a considerar}

\section{Esterilización por calor}

La mayoría de los virus son inactivados a temperaturas entre 56 y $65^{\circ} \mathrm{C}$ mantenida durante 1 hora ya que desnaturaliza las proteínas de la cápside y de la envoltura. Por tanto la 
esterilización por autoclave o calor seco en los parámetros estándares asegura la muerte de todos los virus. ${ }^{(14)}$

\section{Medidas de barrera (EPP/PPE)}

Se conocen también con la sigla EPP por Equipo de Protección Personal o PPE por su sigla en inglés Personal Protective Equipment.

El uso del Equipo de Protección Personal (EPP) dependiendo del nivel de atención es según la Tabla 1

Tabla 1 - Uso de EPP según nivel de atención

\begin{tabular}{|c|c|c|c|c|c|c|}
\hline Nivel de atención & $\begin{array}{l}\text { Higiene de } \\
\text { manos }\end{array}$ & Batas & $\begin{array}{l}\text { Mascarilla } \\
\text { quirúrgica }\end{array}$ & $\begin{array}{c}\text { Respirador (N95 o } \\
\text { F(F2) }\end{array}$ & $\begin{array}{l}\text { Protección } \\
\text { ocular / facial }\end{array}$ & Guantes \\
\hline Triaje & $\sqrt{ }$ & & $\sqrt{ }$ & & & \\
\hline $\begin{array}{c}\text { Procedimiento sin } \\
\text { generación } \\
\text { aerosoles } \\
\end{array}$ & $\sqrt{ }$ & $\sqrt{ }$ & $\sqrt{ }$ & & $\sqrt{ }$ & $\sqrt{ }$ \\
\hline $\begin{array}{l}\text { Procedimiento con } \\
\text { generación } \\
\text { aerosoles }\end{array}$ & $\sqrt{ }$ & $\sqrt{ }$ & & $\sqrt{ }$ & $\sqrt{ }$ & $\sqrt{ }$ \\
\hline
\end{tabular}

Adaptado de: Requerimientos para uso de equipos de protección personal (EPP) para el nuevo coronavirus en establecimientos de salud (OPS, OMS) ${ }^{(15)}$

\section{Mascarillas}

- Las mascarillas quirúrgicas no pueden utilizarse en caso que la intervención implique la generación de aerosoles en cuyo caso deberán utilizarse mascarillas respiratorias o autofiltrantes (FFP2 o N95). (16-17)

En Reino Unido se maneja la FFP3 con mayor capacidad filtrante (98\%) (18) Es preferible que no tengan válvula exhalatoria y si tuviesen se recomienda poner una mascarilla quirúrgica encima $(16,17)$

- Las mascarillas respiratorias (como N95) se utilizan durante la atención de pacientes con infecciones respiratorias transmitidas por partículas aéreas (17) 
Es decir que para cualquier infección respiratoria se recomienda el uso de mascarillas respiratorias y por tanto no es excepción frente al COVID-19 por ser una enfermedad de este tipo. ${ }^{(18)}$

- Con las mascarillas respiratorias se debe hacer una verificación del sello facial cada vez que se utilizan para minimizar la fuga de aire. Como puede diferir según la mascarilla hay que revisar lo que recomienda el fabricante. ${ }^{(17)}$ El testeo consiste en una prueba de cierre positivo que consiste que al exhalar no se debe sentir aire y prueba de cierre negativo al inhalar no se debe sentir aire y la mascarilla debe acercarse al rostro. ${ }^{(19)}$

- Para colocarse se debe sostener en la palma y colocar primero en barbilla. La cinta superior por encima de la oreja y la inferior a la altura del cuello, no deben entrecruzarse ambas cintas ${ }^{(19)}$

- EI ECDC (European Centre for Disease Prevention and Control) en 2014 mencionó que las mascarillas respiratorias no siempre están certificadas contra salpicaduras en particular las que poseen válvula exhaladora. Para sortear esta situación sugirió completar la colocación sobre la mascarilla respiratoria de una mascarilla quirúrgica. (20)

- Tanto las mascarillas quirúrgicas como respiradores se descartan con cada paciente. La contaminación de la superficie del respirador puede ser evitada colocando encima una mascarilla quirúrgica o colocando una pantalla facial. Dada la escasez de ambas mascarillas durante la pandemia se han propuesto métodos de esterilización pero aún no son concluyentes los resultados. ${ }^{(21)}$

- Una forma menos protectora que los respiradores es utilizar una mascarilla quirúrgica con un escudo facial; el uso únicamente de una mascarilla quirúrgica puede ser considerado de alto riesgo en la transmisión comunitaria. ${ }^{(22)}$ 


\section{Consideraciones EPP}

- Se debe hacer uso obligatorio de elementos de bioseguridad similares al pabellón quirúrgico para disminuir el riesgo de contagio, pantalla facial y mascarilla por el riesgo de nuestra profesión en la categoría de exposición/transmisión. (23)

- Los procedimientos que generen aerosoles y que por tanto expongan al personal a patógenos respiratorios implica en forma obligatoria el uso de material de protección PPE (mascarilla respiratoria y protección ocular o pantallas faciales) independientemente de que haya síntomas de infección respiratoria. ${ }^{(24)}$

- Los protocolos actuales recomiendan el uso de mascarilla FFP2 o N95, gorro, guantes, protección ocular o pantalla facial, bata desechable impermeable y cubrezapatos. ${ }^{(25)}$

- En algunos protocolos se menciona el doble par de guantes ${ }^{(25)}$ si bien el CDC no lo recomienda para procedimientos de rutina $(26,27)$, sí puede ser beneficioso para procedimientos con riesgo de pinchazos como cirugías. (26)

- Si bien ciertos protocolos no recomiendan actualmente gorro y zapatones para pacientes COVID-19 para el cuidado rutinario sí se recomienda cuando hay un alto nivel de riesgo. (28) Nosotros entendemos que en este momento puede ser beneficioso el agregado de zapatones/gorro en todos los procesos que generen aerosoles.

Colocación y retiro de EPP

Un estudio realizado en $2015^{(29)}$ determinó que en simulacros de retiro de guantes y bata se produjo contaminación de piel y ropa en casi la mitad de los casos. También que la contaminación se produjo más frecuentemente en el retiro de guantes que en el retiro de la bata.

Se ha comprobado que normalmente se invierte menos tiempo en el retiro del EPP que en la colocación y cuando se aumenta 10 segundos el tiempo de retiro del EPP reduce significativamente la posibilidad de contaminación. (19) 


\section{Algunas consideraciones:}

- Más cantidad de capas de barrera no necesariamente previene el contagio y puede llegar a empeorar la situación ya que puede complicar el retiro y por tanto aumentar el contagio. Lo importante es utilizarlas adecuadamente. ${ }^{(19)}$

- Las técnicas estándar mencionan retirar primero los guantes y luego la bata pero hoy existe un segundo enfoque que es el retiro simultáneo de ambas prendas. $(19,30)$

- El frotado con alcohol de los guantes sólo es posible con los de nitrilo. ${ }^{(19)}$

- Debe haber una zona para la colocación del equipo protector y otra para el retiro

- Hay que moldear la mascarilla alrededor de la nariz en el momento de la colocación y cuidar el ajuste de la misma al rostro ${ }^{(19)}$

- Es recomendable recoger el pelo y quitar caravanas que pueden entorpecer la colación y retiro del equipo ${ }^{(19)}$

Según pudimos constatar el orden de colocación y retiro $(27,30)$ no se aparta de las normas estándares si bien dependiendo del procedimiento pueden agregarse nuevas etapas y en el contexto actual se recomienda el uso de ciertas barreras.

A modo de recordatorio el orden de colocación de barreras es según se ilustra en la Figura 2.

Figura 2 - Orden de colocación de barreras (ilustración original)

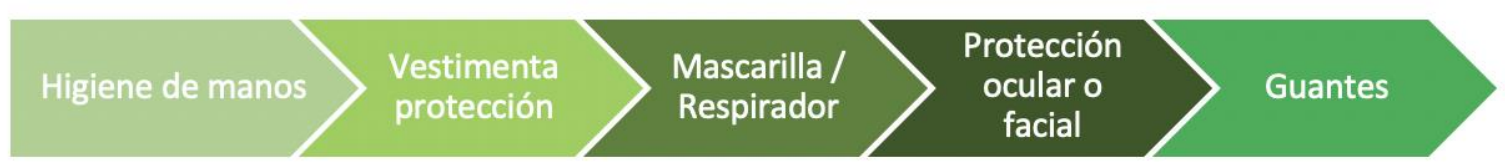

Figura 3 - Secuencia de colocación de barreras 


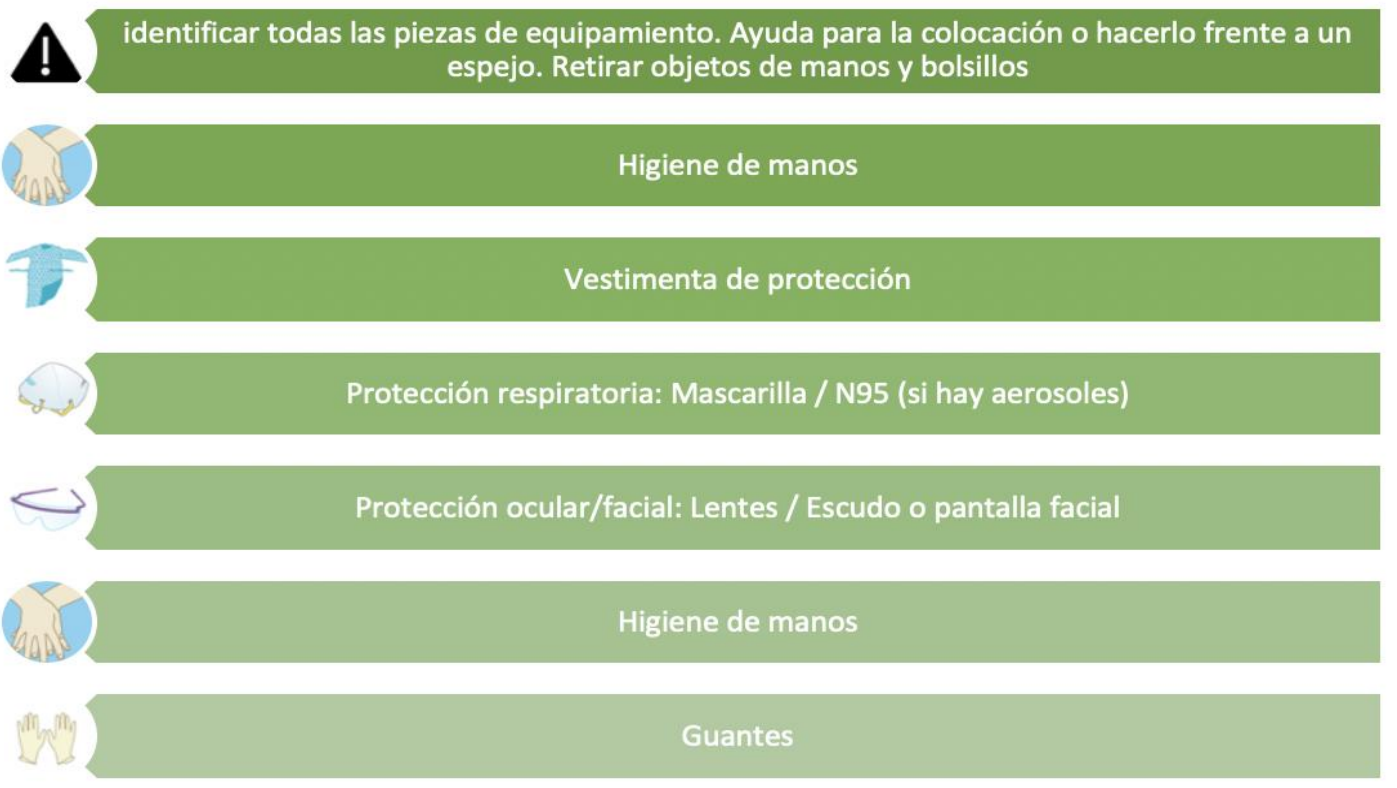

Dibujos extraídos CDC. Basado en el orden de colocación de barreras basado en la OMS y CDC.

Dependiendo del procedimiento pueden agregarse otros medidas de barrera como se ilustra en la Figura 4.

A efectos de identificar modificaciones o agregados al esquema anterior se señala con rojo. (MSP)

Figura 4 - Secuencia de colocación de barreras con modificaciones y agregados en rojo

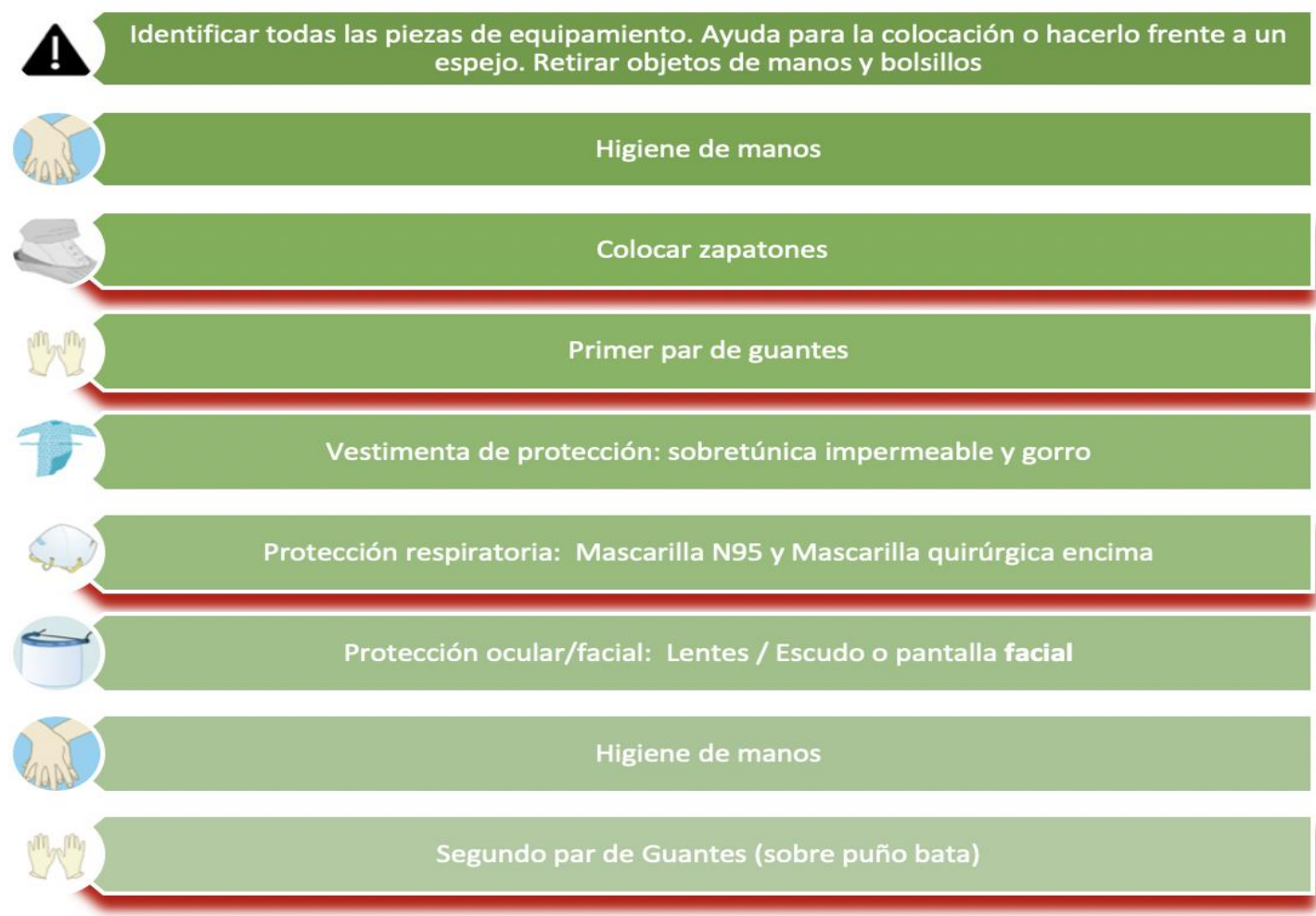

Dibujos extraídos CDC 
Cuadro 1. Puntos a considerar para la colocación del EPP

\section{COLOCACIÓN DE EPP (19)}

Contar con cartelería con los pasos para colocación del EPP

Se recomienda previo a la colocación, identificar todas las piezas del EPP y solicitar ayuda o realizarlo frente a un espejo (27)

Retiro de objetos personales de manos y bolsillos como anillos, relojes, etc.

Anudar la bata al costado y atrás para facilitar retiro y no al frente para minimizar contaminación

La colocación de los lentes debe hacerse de atrás hacia adelante asegurando que al colocarlos no se mueva la mascarilla que ya había sido testeada en su ajuste y posición.

Los guantes colocarlos sobre el puño de la bata

Figura 5 - Orden de retiro de barreras

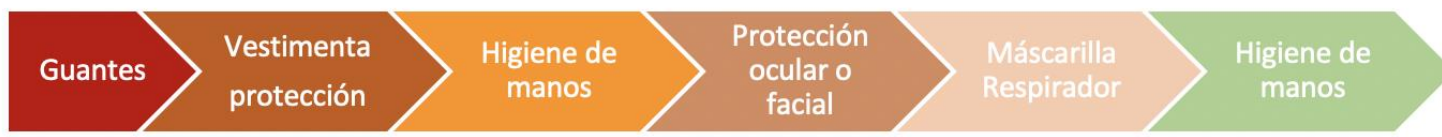

A modo de recordatorio el orden de eliminación de barreras es según la Figura 5 donde ejemplificamos como es el orden en donde se prioriza ir retirando desde lo más contaminado hacia lo menos contaminado. $(27,30)$. Observe las figuras 6 y 7 con 2 técnicas de secuencia de retiro de las barreras. En el caso del primer ejemplo que considera el uso de un doble par de guantes y en qué momentos se retira cada par se basa en el CDC y MSP, pero tener en cuenta que hay otros protocolos aceptados (ver capítulo COVID-19 y la Cirugía Bucomaxilofacial). 
Figura 6 - Secuencia de retiro de barreras (ejemplo 1)

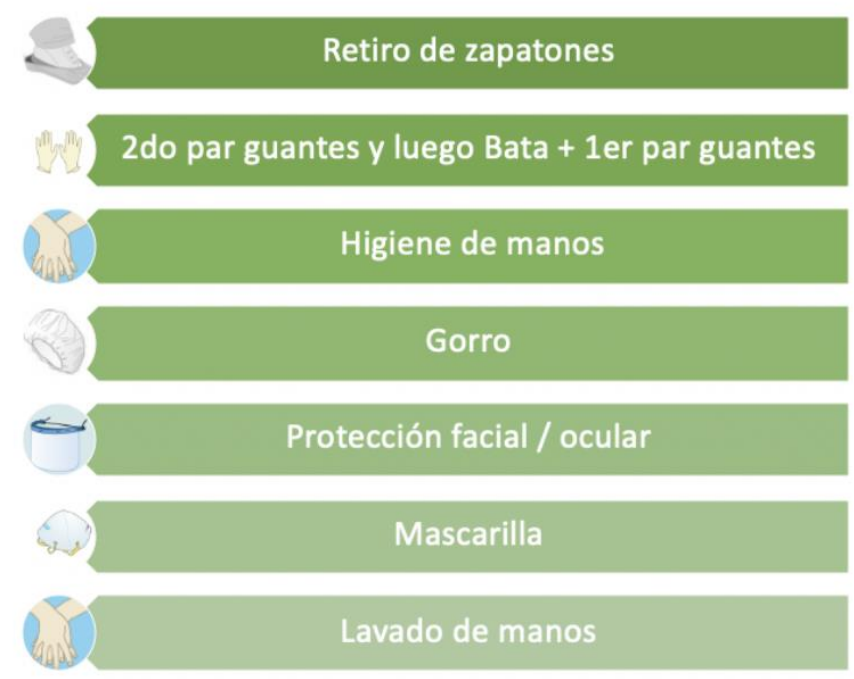

Dibujos extraídos CDC. Basado en referencias ${ }^{(19,30-31)}$

Figura 7 - Secuencia de retiro de barreras (ejemplo 2)

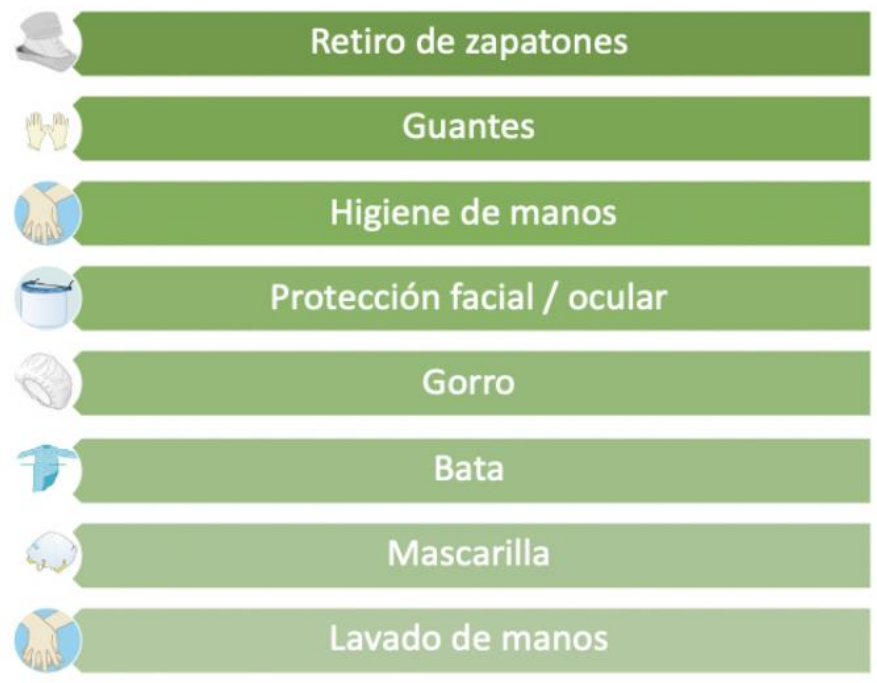

Dibujos extraídos CDC. Basado en referencias $(30,31)$ 
Cuadro 2. Puntos a considerar para el retiro del EPP - Normas generales

RETIRO DE EPP - Normas generales (1 de 3) (19)

Contar con cartelería con los pasos para retiro del EPP

Higiene de manos con alcohol gel luego del retiro de cada prenda

Lavado de manos con agua y jabón al final del retiro del EPP

Tachos grandes de basura para no tener que estar introduciendo la mano para desechar

Cuadro 3. Punto-+88/5966+s a considerar para el retiro del EPP - Retiro de guantes y bata

RETIRO DE EPP - Retiro guantes y bata (2 de 3) (19)

Retiro de guantes tocando contaminado-contaminado y limpio-limpio y después del retiro de guantes frotar manos con alcohol (19). Consultar retiro guantes en Manual Bioseguridad en Odontología (32).

El retiro de guantes y bata se realiza en el área contaminada (donde se atendió el paciente)

Se recomienda el retiro y descarte de la bata y los guantes en forma simultánea salvo cuando se tienen dos pares de guantes donde se retira el primer par y se descarta y luego se procede a retirar la bata con el segundo par de guantes.

El guante tiene que ser del tamaño apropiado porque sino puede complicar el procedimiento de retiro simultáneo.

La bata se retira tomándolo con el guante (parte exterior de la bata) ya que ambos se van a desechar juntos

Bata se retira lentamente (para evitar aerosoles) y arrolla, y una vez armado dicho "rollo" se retiran los guantes en su interior, dejando la parte no contaminada (interior) de la bata hacia afuera (ver figura 8)

Frotar con alcohol en gel las manos 
Figura 8: Retiro simultáneo bata y guantes

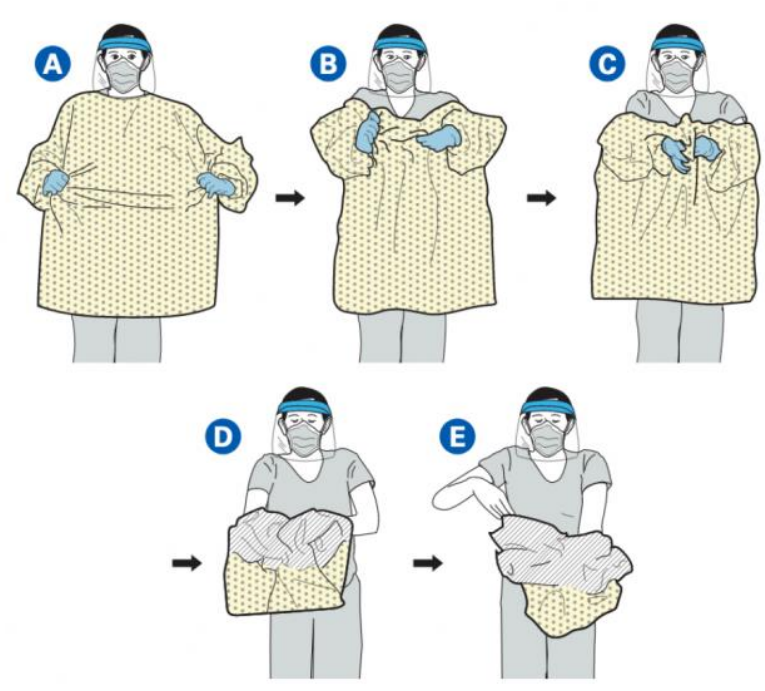

Extraído de $\mathrm{CDC}^{(30)}$

Tironear de la bata desde adelante apartándola del cuerpo de forma con los guantes. Empezar a enrollar con la parte interna de la bata hacia afuera. Mientras se va enrollando la bata, quitarse los guantes al mismo tiempo solo tocando la parte interna del guante y bata con sus manos Descartar ambos. ${ }^{(23,30)}$

Cuadro 4. Puntos a considerar para el retiro del EPP - Retiro de protección ocular/facial y mascarilla

\section{RETIRO DE EPP - Retiro de protección ocular/ facial y mascarilla (3 de 3) (19)}

Nunca tocar la parte exterior de la mismas porque están contaminadas (30)

Retiro de escudo facial

Retiro de protección ocular siempre de atrás (piezas traseras - patillas de gafas)

Retiro de mascarilla respirador primero cinta inferior, luego superior y luego alejarla de la cara

Estos equipos de protección respiratoria (mascarilla) deben quitarse en último lugar, luego de otros componentes como guantes, batas, etc. (31)

Retiro de mascarilla /escudo facial fuera del sitio de atención (33)

Lavado de manos con agua y jabón al final del retiro del EPP 


\section{Limpieza de manos}

Se considera una de las medidas más críticas para reducir el riesgo de transmisión a pacientes.

Se mantienen los 5 momentos para la higiene manual recomendada por la OMS (18):

- Antes de tocar a un paciente

- Antes de procedimientos limpios/asépticos

- Después de exposición o riesgo de exposición a líquidos corporales

- Después de tocar a un paciente

- Después de tocar los alrededores de un paciente

El lavado de manos es el habitual. Consultar procedimiento en Manual de Bioseguridad en Odontología. ${ }^{(32)}$

Se recomienda el lavado de manos de entre 40 a 60 segundos con agua y jabón líquido y enjuague ${ }^{(18)}$

En resumen, se siguen las mismas recomendaciones que en la práctica habitual.

\section{Desinfección de superficies}

$\mathrm{Si}$ bien, tal como fue mencionado, SARS-CoV-2 puede permanecer mucho tiempo en distintas superficies, al ser un virus envuelto debería ser destruido incluso por agentes desinfectantes de nivel bajo.

El alcohol o los productos basados en el acohol son efectivos contra los virus envueltos para desintegrar los lípidos protectivos. Los productos de amonio cuaternario también ya que atacan estructuras proteicas y lipídicas. La lejía y otros oxidantes potentes descomponen rápidamente componentes esenciales del virus. ${ }^{(34)}$

La limpieza de superficies es una parte esencial de la desinfección dado que la materia orgánica puede inactivar muchos desinfectantes. La remoción de virus como el que produce el COVID-19 requiere de una limpieza profunda seguida de desinfección. (35) 


\section{Desinfectantes activos contra SARS-CoV-2:}

Los desinfectantes activos frente a los coronavirus que son considerados las mejores elecciones ${ }^{(36)}$ para situaciones clínicas al momento son:

- el hipoclorito de sodio en una concentración de 1000 ppm disponible de cloro y

- el etanol en concentraciones entre $70-90 \%$.

Tanto para el hipoclorito de sodio como con el etanol la limpieza previa es esencial ${ }^{(35)}$

Los anteriores agentes químicos son los más mencionados actualmente, pero también aparecen otros como el peróxido de hidrógeno al $0.5 \%$ De todas maneras, muchos estudios infieren que este virus se comporta igual que otros coronavirus como el SARS-CoV-1. (37)

Si bien los compuestos de amonio cuaternario, tal como el cloruro de benzalconio, tienen una propiedad dual detergente y desinfectante y pueden ser una alternativa adecuada, debe verificarse su acción según estándares (ej. EPA) en la clínica donde la carga viral en superficies puede ser alta. ${ }^{(38)}$

Dado que las condiciones para inactivar al SARS-CoV-2 están comprendidas en los desinfectantes y condiciones estándar, es necesario aplicar estas últimas.

A modo de ejemplo, si este virus se inactiva a una concentración de 1000 ppm en 10 minutos pero las condiciones estándar para que inactive otros gérmenes son mayores, las recomendaciones serán éstas últimas. Nos interesa puntualizar que es importante utilizar las mismas técnicas que se utilizan normalmente para que asegure que también otros gérmenes más difíciles de inactivar queden contemplados.

La ventaja de que este virus se inactive en menores concentraciones y tiempo permite asegurar que queda contemplado en los tiempos recomendados estándar.

Las recomendaciones estándar para limpieza de superficies son utilizar hipoclorito de sodio entre 1000 ppm ( $0.1 \%)$ a 5000 ppm (0.5\%) en mesas de trabajo o el piso si está muy sucio o contaminado con sangre o zonas críticas o zonas con manchas de materia orgánica. Alcohol $70^{\circ}$ si la superficie no admite el uso de hipoclorito. ${ }^{(32)}$

A continuación se presenta una tabla con estos desinfectantes, sus acciones y buenas prácticas. 
Tabla 2. Desinfectantes efectivos contra SARS-CoV-2.

\begin{tabular}{|c|c|c|c|}
\hline $\begin{array}{c}\text { Limpieza } \\
\text { (mesas de trabajo, } \\
\text { sillones) e } \\
\text { instrumental }\end{array}$ & $\begin{array}{c}\text { Limpieza con } \\
\text { detergente }\end{array}$ & $\begin{array}{c}\text { Dipoclorito al 0.5\% } \\
\text { o }\end{array}$ & $\begin{array}{c}\text { Otras } \\
\text { consideraciones/ } \\
\text { buenas prácticas }\end{array}$ \\
$\begin{array}{c}\text { Cobertores } \\
\text { descartables en toda } \\
\text { la superficie de } \\
\text { contacto con el } \\
\text { cuerpo del paciente, } \\
\text { foco,etc. }\end{array}$ \\
\hline Manchas orgánicas & $\begin{array}{c}\text { Limpieza con } \\
\text { detergente }+\end{array}$ & $\begin{array}{c}\text { Hipoclorito al 0.5\% } \\
\text { (hasta 1\% en caso de } \\
\text { derrames } \\
\text { importantes ) o }\end{array}$ & $\begin{array}{c}\text { Cobertores } \\
\text { descartables en toda } \\
\text { la superficie de } \\
\text { contacto con el } \\
\text { cuerpo del paciente, } \\
\text { foco,etc. }\end{array}$ \\
& Etanol 70\% & Etanol 70\% & \\
\hline Pisos & $\begin{array}{c}\text { Lavado con } \\
\text { detergente }\end{array}$ & Hipoclorito al 0.1\% & $\begin{array}{c}\text { Técnica del doble } \\
\text { balde }\end{array}$ \\
\hline
\end{tabular}

\section{Guía para obtener la concentración requerida}

Como guía para lograr una solución de hipoclorito a esa concentración utilizar la siguiente fórmula:

$\mathrm{V} 1=\underline{(\mathrm{C} 2 \times \mathrm{V} 2)}$

C1

Donde C2 = concentración que se quiere lograr; V2 = volumen que se desea preparar; $\mathrm{C} 1$ = concentración original (en la etiqueta del fabricante); V1 = volumen a utilizar del producto original

Por ejemplo, si desea preparar 1 litro de 1000 ppm ( $1 \mathrm{gr} / \mathrm{tt}-0.1 \%)$ a partir una solución original que contiene $40 \mathrm{gr} / /$ itro de cloro sería:

$\mathrm{V} 1=\underline{(1 \mathrm{gr} / \mathrm{lt} \times 1000 \mathrm{ml})}$

$\mathrm{V} 1=25 \mathrm{ml}$ $40 \mathrm{gr} / \mathrm{tt}$

Se deberá entonces tomar $25 \mathrm{ml}$ de la solución original en $975 \mathrm{ml}$ de agua. 
Cuadro 5. Puntos a considerar al finalizar el tratamiento

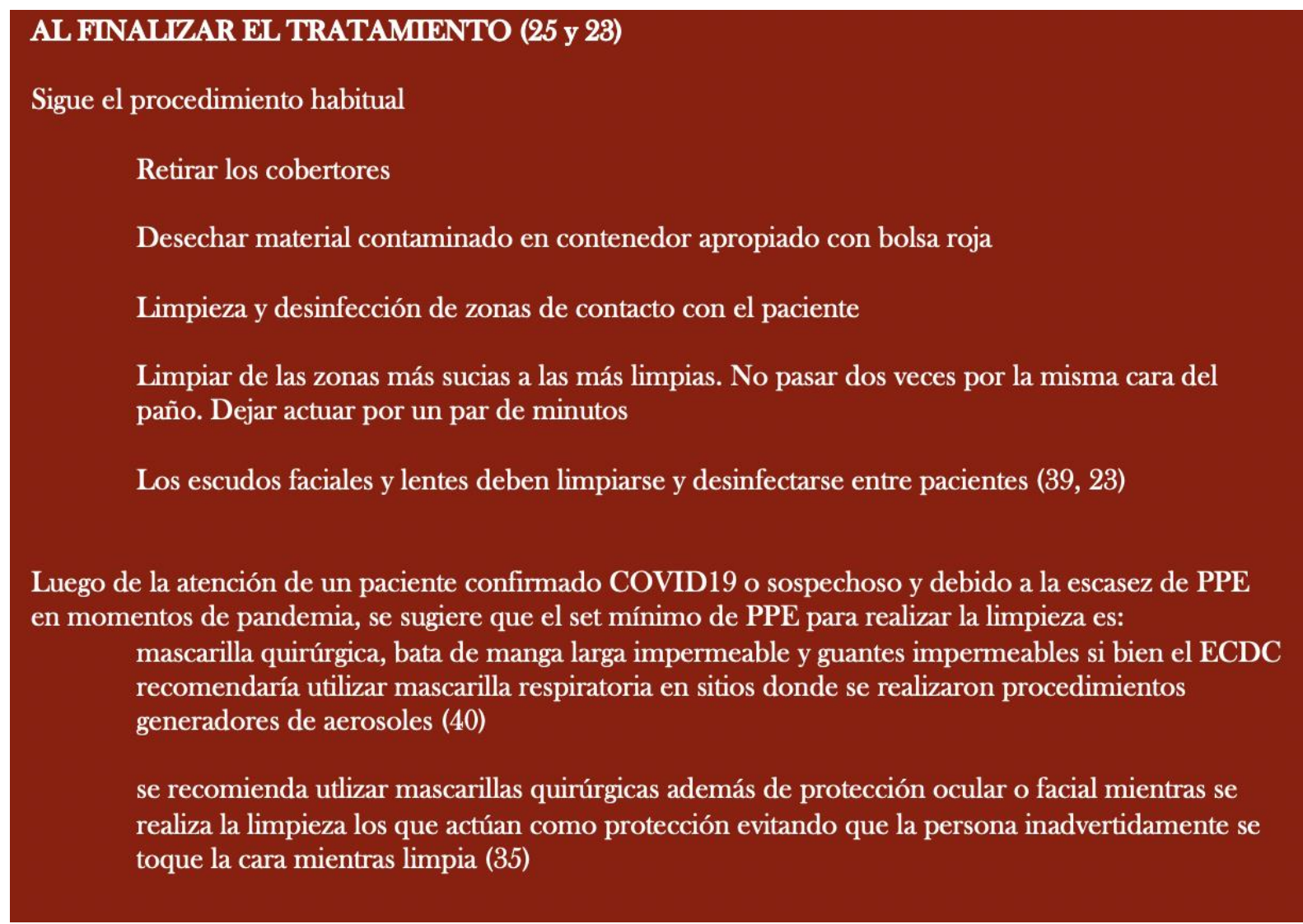

Lavado de ropa

Se debe lavar por separado de la ropa común o doméstica, con agua caliente de preferencia $60^{\circ} \mathrm{C}$ o superior durante 10 minutos lo que destruirá muchas bacterias y también este virus. (31)

De todas formas, para destruir este microorganismo es suficiente detergente que pueda hacer abundante espuma, por lo que que en un proceso de lavado a máquina es suficiente para garantizar que la ropa queda libre del virus. ${ }^{(41)}$

\section{Control del aire}

Es conocido el efecto del uso de la radiación ultravioleta para la inactivación de microorganismos de superficies y ambientes, en particular en quirófanos. Con la irrupción de este virus han aparecido varios reportes promocionando lámparas para el uso en las clínicas.

Es compleja su utilización a través de lámparas portátiles ya que depende de instalación correcta en relación al espacio. Se deberá tener cuidado de evitar exposición por sus efectos. En cuanto a los purificadores de ozono si bien algunos purificadores tienen número de EPA, ésta no certifica dispositivos purificadores de aire. De hecho no es efectivo utilizado a concentraciones que no superen los estándares de salud. ${ }^{(42)}$ 
En lugares sin posibilidad de ventilación y sus sistemas de ventilación son circuitos cerrados, se mantiene recomendación de la utilización de filtros HEPA (High-efficiency particulate area). (40)

Manejo de residuos

No hay cambios respecto al manejo de residuos

\section{Referencias}

1) Rabi FA, Al Zoubi MS, Kasasbeh GA, Salameh DM, Al-NasserA.D. SARS-CoV-2 and Coronavirus Disease 2019: What We Know So Far. Pathogens 2020 Mar, 9(3), 231. Disponible en: https://www.mdpi.com/2076-0817/9/3/231/htm Acceso 4/4/2020

2) Meng L, Hua F, Bian Z, Coronavirus Disease 2019 (COVID-19): Emerging and Future Challenges for Dental and Oral Medicine, JDR 2020 Mar; Disponible en: https://journals.sagepub.com/doi/10.1177/0022034520914246\#articleCitationDownloadCont ainer

Acceso 4/4/2020

3) The Internet Book of Critical Care COVID-19. Disponible en:

\section{https://emcrit.org/wp-content/uploads/2020/03/COVID-19-EMCrit-Project3-16.pdf}

Acceso 4/4/2020

4) CORONAVIRUS: COVID-19 Informe técnico; 2020 Mar; Dissponible en https://www.portalfarma.com/Profesionales/campanaspf/Asesoramiento-salud-

publica/infeccion-coronavirus-2019-nCoV/Documents/Informe-tecnico-Coronavirus.pdf

Acceso 5/4/2020

5) Liébana J (2002) Microbiología Oral. Madrid, España: McGraw-Hill.

6) Walls AC, Park Y, Tortorici MA, Wall A, McGuire AT, Veesler D, Structure, Function, and Antigenicity of the SARS-CoV-2 Spike Glycoprotein. Cell, 181(2): 2020 Abr, 281-292. Disponible en: https://www.sciencedirect.com/science/article/pii/S0092867420302622. Acceso 6/5/2020

7) Hunt R. Coronavirus, gripes y Síndrome Respiratorio Agudo Severo (SARS). Microbiológica e Inmunología On-line- Virología - . Disponible en:

https://www.microbiologybook.org/Spanish-Virology/spanish-chapter25.htm

Acceso 4/4/2020 
8) Peng X, Xu X, Li Y, Chen L, Zhou X, Ren B, Transmission routes of 2019-nCov and controls in dental practice, Int J Oral Sci 2020; 12(1). Disponible en:

https://www.researchgate.net/publication/339650518 Transmission routes of 2019-

$\underline{\mathrm{nCoV}}$ and controls in dental practice

Acceso 5/4/2020

9) Xu H, Zhong L, Deng J, Peng J, Dan H, Zeng C, Li T, Chen Q. High expression of ACE2 receptor of 2019-nCoV on the epithelial cells of oral mucosa. Int J Oral Sci 2020; 12(1). Disponible en:

https://www.nature.com/articles/s41368-020-0074-x

Acceso 30/4/2020

10) Estados Unidos de Norteamérica. CDC - Interim Infection Prevention and Control Recommendations for Patients with Suspected or Confirmed Coronavirus Disease 2019 (COVID-19) in Healthcare Settings; Disponible en:

https://www.cdc.gov/coronavirus/2019-ncov/hcp/infection-control-

recommendations.html?CDC AA refVal=https\%3A\%2F\%2Fwww.cdc.gov\%2Fcoronavirus $\%$ 2F2019-ncov\%2Finfection-control\%2Fcontrol-recommendations.html Acceso 12/4/2020

11) Gandhi M, Yokoe DS, Havlir DV, Asymptomatic Transmission, the Achilles' Heel of Current Strategies to Control Covid-19, New England J Med 2020 Apr; Disponible en:

https://www.nejm.org/doi/full/10.1056/NEJMe2009758.

Acceso 12/4/2020

12) Sandoui A. Why does SARS-CoV-2 spread so easily? Medical News Today; 2020 Mar; Disponible en:

https://www.medicalnewstoday.com/articles/why-does-sars-cov-2-spread-so-easily\#Spikeprotein-on-the-new-coronavirus

Acceso 5/4/2020

13) Manzanares R, Manzanares A; El Covid-19, ese enemigo invisible. Dental Tribune 2020. Disponible en

\section{https://la.dental-tribune.com/news/el-covid-19-ese-enemigo-invisible/}

Acceso 5/04/2020

14) Pumarola A, Rodríguez-Torres A, García-Rodríguez JA, Piédrola-Angulo G. Microbiología y Parasitología Médica. 2ed. Barcelona, Salvat Editores, 1987. p584

15) OPS. Requerimientos para uso de equipos de protección personal (EPP) para el nuevo coronavirus (2019-nCoV) en establecimientos de salud. 2020. Disponible en:

https://www.paho.org/es/documentos/requerimientos-para-uso-equipos-proteccionpersonal-epp-para-nuevo-coronavirus-2019-ncov 
Acceso 15/4/2020

16) Organización Colegial de Enfermería. Mascarillas COVID-19,[Infografía] 2020 Mar; Disponible en

https://www.consejogeneralenfermeria.org/covid-19 Acceso 9/4/2020

17) Organización Colegial de Enfermería. Aclaraciones sobre el uso de mascarillas, [Infografía]. 2020 Mar; Disponible en:

https://www.consejogeneralenfermeria.org/covid-19 Acceso 9/4/2020

18) Pankhurst CL, Coulter WA. Protección personal para prevenir el contagio de infecciones.

En: Prevención y control de enfermedades infecciosas en Odontología. Ciudad de México: El Manual Moderno, 2018. p93-100

19) Guerra S, Equipo de Protección Personal (EPP) para la asistencia de pacientes con COVID-19: lo que debemos saber.CONAE Videoconferencia 1: "Uso de EPP en COVID-19" MSP. Disponible en:

https://www.youtube.com/watch?v=n_e6rZfMCFg

Acceso el 17/04/2020

20) European Centre for Disease Prevention and Control. Safe use of personal protective equipment in the treatment of infectious diseases of high consequence. 2014. Disponible en: https://www.ecdc.europa.eu/sites/default/files/media/en/publications/Publications/safe-useof-ppe.pdf

Acceso 11/4/2020

21) European Centre for Disease Prevention and Control. Cloth masks and mask sterilisation as options in case of shortage of surgical masks and respirators. 2020. Disponible en:

https://www.ecdc.europa.eu/en/publications-data/cloth-masks-sterilisation-options-shortagesurgical-masks-respirators

Acceso 11/4/2020

22) American Dental Association, Interim Guidance For Management of Emergency and Urgent Care. Disponible en:

https://www.ada.org/ /media/CPS/Files/COVID/ADA Int Guidance Mgmt Emerg-

Urg Dental COVID19.pdf?utm source $=$ cpsorg\&utm medium $=$ cpsalertbar\&utm content $=c \mathrm{cV}$ -pm-ebd-interim-flowchart\&utm campaign=covid-19

Acceso 20/4/2020

23) Sepúlveda VC, Secchi AA, Donoso-Hofer F., Consideraciones en la Atención Odontológica de Urgencia en Contexto de Coronavirus COVID-19 (SARS-CoV-2), Int J Odontostomat 2020;,14(3):279-284. Disponible en: http://www.ijodontostomatology.com/wpcontent/uploads/2020/03/2020 v14n3 003.pdf 
Acceso: $18 / 04 / 2020$

24) Canadá. Provincial Infectious Diseases Advisory Committee. Routine Practices and Additional Precautions In All Health Care Settings, 3rd edition, 2012. Disponible en:

https://www.publichealthontario.ca/-/media/documents/bp-rpap-healthcare-

settings.pdf?la=en

Acceso 9/4/2020

25) Organización Colegial de Dentistas de España. Consejo Dentistas. Plan Estratégico de Acción para el período posterior a la crisis creada por el COVID-19. 2020 Abr. Disponible en: https://www.consejodentistas.es/comunicacion/actualidad-consejo/notas-de-prensaconsejo/item/1763-plan-estrategico-de-accion-para-el-periodo-posterior-a-la-crisis-creadapor-el-covid-19.html

Acceso: 16/04/2020

26) Shah A, Is Double Gloving Advantageous? Dimensions of Dental Hygiene, 2011 Dec; 9(12): 22- 24

Disponible en:

https://dimensionsofdentalhygiene.com/article/is-double-gloving-advantageous/

Acceso: $18 / 4 / 2020$

27) PAHO. COVID-19. Guidelines for personal protective equipment. [Infografía]. 2020.

https://www.paho.org/en/documents/infographic-covid-19-guidelines-personal-protective-

equipment

Acceso 9/4/2020

28) Australia National Guidelines for Public Health, South Australia Health Public, Health Alert. COVID-19 Personal Protective Equipment Matrix Accesible

en:https:/www.sahealth.sa.gov.au/wps/wcm/connect/952a07a8-a676-4e53-9603-

67c44f2162c3/COVID+assessment+matrix v2+0+\%28FINAL+as+of+24.4.+2020\%29.pdf?

MOD=AJPERES\&amp;CACHEID=ROOTWORKSPACE-952a07a8-a676-4e53-9603-

67c44f2162c3-n6GTr.d

Acceso 26/4/2020

29) Tomas ME, Kundrapu S, Thota P, Sunkesula VC, Cadnum JL; T Mana TS, Jencson A, O'Donnell M, Zabarsky TF, Hecker MT, Ray AJ, Wilson BM, Donskey CJ, Contamination of Health Care Personnel During Removal of Personal Protective Equipment. JAMA Intern Med. 2015;175(12):1904-1910. doi:10.1001/jamainternmed.2015.4535

30) Estados Unidos de Norteamérica. CDC, Sequence for putting on personal protective equipment.[Infografía]. Disponible en: https://www.cdc.gov/hai/pdfs/ppe/PPE-Sequence.pdf Acceso 9/4/20 
31) OMS. Equipo de protección personal. Disponible en:

\section{https://www. who.int/csr/resources/publications/epp-oms.pdf?ua=1}

Acceso 20/4/20

32) Papone Yorio V, Manual de Bioseguridad en Odontología. 2ed. Montevideo: Facultad de Odontología, 2010.

33) American Dental Association, How to Put On and Take Off Personal Protective Equipment. [Video]. Disponible en:

\section{https://www.youtube.com/watch?v=5ajfP06msfM\&list=PLgVW4hDBH0pd0Ncy0Nc0zQgFO}

\section{n3oChGfH\&index=2. Acceso 30/4/20}

34) Jansen K. How we know disinfectants should kill the COVID-19 coronavirus? Disponible en:

https://cen.acs.org/biological-chemistry/infectious-disease/How-we-know-disinfectantsshould-kill-the-COVID-19-coronavirus/98/web/2020/03 Acceso: 5/4/20

35) Australian Government Department of Health. Environmental cleaning and disinfection principles for COVID-19 Disponible en:

https://www.health.gov.au/sites/default/files/documents/2020/03/environmental-cleaningand-disinfection-principles-for-covid-19.pdf

Acceso 11/4/20

36) Government of South Australia, Coronavirus disease (COVID-19): environmental management. Disponible en:

https://www.sahealth.sa.gov.au/wps/wcm/connect/58acb674-262e-4300-ac22-

03177d07aaef/Factsheet+-

+Novel+coronavirus+environmental+management+\%5BNovel+coronavirus\%5D.pdf?MOD= AJPERES\&CACHEID=ROOTWORKSPACE-58acb674-262e-4300-ac22-03177d07aaefn4qLQbV

Acceso 11/4/20

37) Kampf G, Todt D, Pfaender S, Steinmann E. Persistence of coronaviruses on inanimate surfaces and their inactivation with biocidal agents. J Hospital Infect 104(3): 246-251. Disponible en:

https://www.journalofhospitalinfection.com/article/S0195-6701(20)30046-3/fulltext

Acceso 5/4/20

38) Government of South Australia, Cleaning and disinfection in the workplace. COVID-19 Fact Sheet. Disponible en:

https://www.sahealth.sa.gov.au/wps/wcm/connect/3abb2b62-6f07-4051-838b- 


\section{TWORKSPACE-3abb2b62-6f07-4051-838b-b71d090df3ac-n5hDSI6}

Acceso 12/4/20

39) American Dentistry Association, Interim Guidance for Minimizing Risk of COVID-19 Transmission. Disponible en:

https://www.ada.org/ /media/CPS/Files/COVID/ADA_COVID_Int_Guidance_Treat_Pts.pdf?

utm_source=cpsorg\&utm_medium=cpsalertbar\&utm_content=cv-pm-ebd-interimresponse\&utm_campaign $=$ covid -19

40) ECDC Publications \& data: Disinfection of environments in healthcare and non-healthcare settings potentially contaminated with SARS-CoV-2. Disponible en:

https://www.ecdc.europa.eu/en/publications-data/disinfection-environments-covid-19

Acceso 3/5/20

41) AIDIS Uruguay, OPS, OMS. Recomendaciones de saneamiento Ambiental en prevención del COVID-19. Disponible en: https://aidis.org.uy/1655-2/

Acceso: $5 / 4 / 20$

42) Estados Unidos de Norteamérica. Environmental Protection Agency, Ozone generators that are sold as air cleaners. Disponible en:

https://www.epa.gov/indoor-air-quality-iaq/ozone-generators-are-sold-air-cleaners Acceso: $10 / 5 / 20$ 